\title{
Investigation on the Effects of Boron Carbide Particle Size on Radiation Shielding Properties of Boron Carbide-Titanium Diboride Composites
}

\begin{abstract}
B. Buyuk ${ }^{a}$, A.B. Tugrul ${ }^{a}$, S. AKtop ${ }^{b}$ And A.O. AdDemir ${ }^{b}$
${ }^{a}$ ITU Energy Institute, Nuclear Researches Division, Ayazaga Campus 34469, Maslak/Istanbul, Turkey ${ }^{b}$ ITU Metallurgical and Materials Engineering Faculty, Ayazaga Campus 34669, Maslak/Istanbul, Turkey

Boron carbide is a material which has wide application areas in industry including nuclear technology. Titanium diboride-boron carbide composites which were produced from different boron carbide particle sizes were studied for searching of the behaviour against the gamma ray. Micron size and submicron size boron carbide were used to produce composite materials. The volume of boron carbide and titanium diboride in the composites are $85 \%$ and $15 \%$, respectively. For the investigation of the gamma radiation behaviour of these materials, Cs- 137 radioisotope was used as gamma source in the experiments which has a single gamma-peak at $0.662 \mathrm{MeV}$. Gamma transmission technique was used for the measurements. The effects of boron carbide particle size on radiation attenuation of titanium diboride-boron carbide composites were evaluated in relation with gamma transmission and the results of the experiments were interpreted and compared with each other. It could be understood that decrease of particle size of boron carbide in boron carbide-titanium diboride composites causes higher linear and mass attenuation coefficient values. So, submicron size boron carbide used composite materials are more convenient than micron size boron carbide used composite materials as radiation shielding materials for nuclear applications.
\end{abstract}

DOI: $10.12693 /$ APhysPolA.123.177

PACS: 25.20.Dc

\section{Introduction}

Boron carbide has low-density, high hardness and corrosion resistance, chemical stability and high neutron capture feature $[1,2]$. So, boron carbide has wide application areas in industry. Some of these areas are the nuclear technology, military industry, ceramic industry and air-space industry [1, 2]. Some boron carbide application fields are sand blasting nozzles, nuclear reactors, reactor control rods and the radiation shielding materials [2, 3]. However, boron carbide is brittle, has low strength and high temperature sintering properties $[3,4]$. Since the sintering of pure boron carbide to high densities is difficult, specific additives such as $\mathrm{SiC}, \mathrm{Al}_{2} \mathrm{O}_{3}, \mathrm{TiB}_{2}, \mathrm{AlF}_{3}$, $\mathrm{W}_{2} \mathrm{~B}_{5}$, elemental boron and carbon have been used as sintering aids to increase the sintered density [2-5].

In this study, boron carbide-titanium diboride composites which were produced from different boron carbide particle sizes were studied for searching of the behaviour against the gamma ray. For the investigation of the gamma radiation behaviour of these materials, Cs-137 radioisotope was used as gamma source in the experiments which has a single gamma-peak at $0.662 \mathrm{MeV}$ and half life is $30.1 \mathrm{y}[6,7]$.

Gamma transmission technique was used for the measurements. In the experiments, gamma peaks were measured with PM1401K model, scintillation detector and multi-channel analyzer. All the measurements were implemented by taking at least three counts in the same geometry.

Different boron carbide particle size ratios in boron carbide-titanium diboride composites were evaluated in relation with gamma transmission and the results of the experiments were interpreted and compared with each other.

\section{Experiments and materials}

This gamma transmission technique is based on penetrating gamma rays through materials. Materials were put between the detector and gamma source within same axis. The gamma radiation counts are measured reaching to detector from the source. The counts with material and without material are compared and evaluated [6-8]. Figure 1 shows schematic view of gamma transmission technique.
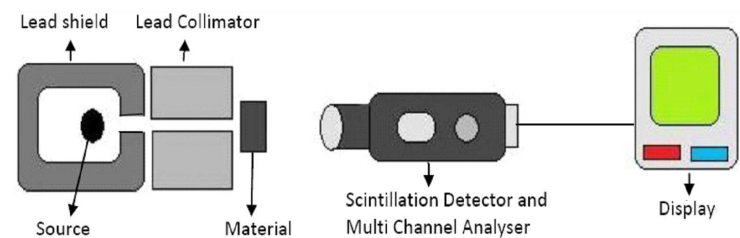

Fig. 1. Schematic view of gamma transmission technique.

The radiation passing through the material is calculated by the following equation:

$$
I=I_{0} \mathrm{e}^{-\mu x}
$$

where $I$ and $I_{0}$ are the transmitted and initial gamma ray intensities, respectively, $\mu$ is linear attenuation coefficient of material at specific $\gamma$-ray and $x$ is the thickness of the material.

The materials which were used in the experiments have different boron carbide particle size ratios in the compos- 
ites. Thus they are coded according to their boron carbide and titanium diboride ratios by volume in composites and particle size ratios. Table I shows the materials that are used in the experiments and their ratios by volume in the composite materials and also their strength, hardness and density properties. Average particle size for unmilled boron carbide and titanium diboride particles are $3.997 \mu \mathrm{m}$ and $4.365 \mu \mathrm{m}$, respectively. For nanoscale boron carbide, materials were milled for half an hour in attritor. The average particle size for nanoscale boron carbide particles is $405 \mathrm{~nm}$.

TABLE I

The contents and strength, hardness, density properties of the composite materials [5].

\begin{tabular}{c|c|c|c|c|c|c}
\hline \hline $\begin{array}{c}\text { Material } \\
\text { (code) }\end{array}$ & \multicolumn{2}{|c|}{$\begin{array}{c}\text { Boron carbide [vol.\%] } \\
\text { Sub micron }\end{array}$} & $\begin{array}{c}\text { Titanium diboride } \\
{[\text { vol.\%] }}\end{array}$ & $\begin{array}{c}\text { Hardness } \\
\text { (Vickers })\end{array}$ & $\begin{array}{c}\text { Strength } \\
{[\mathrm{MPa}]}\end{array}$ & $\begin{array}{c}\text { Density } \\
{\left[\mathrm{g} / \mathrm{cm}^{3}\right]}\end{array}$ \\
\hline 8515 & 85 & - & 15 & $363 \pm 16$ & $2952 \pm 149$ & 2.685 \\
$8515-1 / 2$ & 42.5 & 42.5 & 15 & $375 \pm 51$ & $3146 \pm 146$ & 2.714 \\
$8515-\mathrm{M}$ & - & 85 & 15 & $343 \pm 68$ & $2843 \pm 182$ & 2.751
\end{tabular}

TABLE II

Results for $8515,8515-1 / 2$ and 8515-M boron carbide-titanium diboride composites with Cs-137 gamma source for accumulation time $600 \mathrm{~s}$.

\begin{tabular}{c|c|c|c|c|c|c|c}
\hline \hline \multirow{2}{*}{ Materials } & Thickness [cm] & \multicolumn{3}{|c|}{ Net count } & $\begin{array}{c}\text { Average } \\
\text { count }\end{array}$ & $\begin{array}{c}\text { Standard } \\
\text { deviation }\end{array}$ & $\begin{array}{c}\text { Relative } \\
\text { count }\end{array}$ \\
\hline \multirow{5}{*}{8515} & 0 & 1 & 2 & 3 & 8048 & 45 & 1.000 \\
& 0.4565 & 7440 & 7422 & 7438 & 7434 & 10 & 0.924 \\
& 0.9343 & 6747 & 6716 & 6842 & 6769 & 66 & 0.841 \\
& 1.3864 & 6250 & 6234 & 6216 & 6233 & 17 & 0.775 \\
& 1.8552 & 5798 & 5784 & 5818 & 5800 & 17 & 0.721 \\
& 2.31 & 5281 & 5292 & 5299 & 5291 & 9 & 0.657 \\
\hline \multirow{5}{*}{$8515-1 / 2$} & 0 & 7951 & 7949 & 8059 & 7986 & 63 & 1.000 \\
& 0.4573 & 7298 & 7363 & 7358 & 7340 & 36 & 0.919 \\
& 0.9191 & 6765 & 6700 & 6689 & 6718 & 41 & 0.841 \\
& 1.3855 & 6222 & 6163 & 6148 & 6178 & 39 & 0.774 \\
& 1.8615 & 5632 & 5700 & 5679 & 5670 & 35 & 0.710 \\
& 2.325 & 5166 & 5174 & 5219 & 5186 & 28 & 0.649 \\
\hline \multirow{3}{*}{$8515-\mathrm{M}$} & 0 & 8043 & 7959 & 7953 & 7985 & 50 & 1.000 \\
& 0.4493 & 7294 & 7287 & 7244 & 7275 & 27 & 0.911 \\
& 0.8886 & 6679 & 6660 & 6745 & 6695 & 45 & 0.838 \\
& 1.3405 & 6202 & 6139 & 6187 & 6176 & 33 & 0.773 \\
& 1.7909 & 5690 & 5682 & 5658 & 5677 & 17 & 0.711 \\
& 2.2506 & 5252 & 5224 & 5192 & 5223 & 30 & 0.654
\end{tabular}

For production of submicron boron carbide, boron carbide materials were milled in Spex 8000 mill for 30 min with WC balls. Particle size distribution of unmilled and milled boron carbide are given in Fig. 2 .

With milling the boron carbide, average particle size was decreased from $3.997 \mu \mathrm{m}$ to $405 \mathrm{~nm}$. All composite materials were sintered at $2250^{\circ} \mathrm{C}$ for $1 \mathrm{~h}$ under $50 \mathrm{MPa}$ pressure. The materials which were used in the experiments have about $1 \times 0.5 \times 2 \mathrm{~cm}^{3}$ dimensions. Cs-137 gamma radiation source which has $8.9 \mu \mathrm{Ci}$ was used in the experiments. Lead blocks were used for radiation shielding and collimation. The collimator diameter is $7 \mathrm{~mm}$. The distance between the detector and source is $10 \mathrm{~cm}$.
Firstly background radiation was measured. Then Cs-137 gamma source was set. Initial intensity count $\left(I_{0}\right)$ was measured. Then materials were set and intensity counts $(I)$ were measured for all thickness values. All counts were measured three times for $600 \mathrm{~s}$ and net counts calculated by reducing background value. Average values and standard deviations were calculated. For rational evaluating, relative intensity $\left(I / I_{0}\right)$ values were calculated. Results were given in tables. Relative intensitymaterial thickness graph was drawn for each titanium diboride ratio. Exponential distribution was shown on graphs and exponential equations were calculated. Then results were evaluated and discussed. 


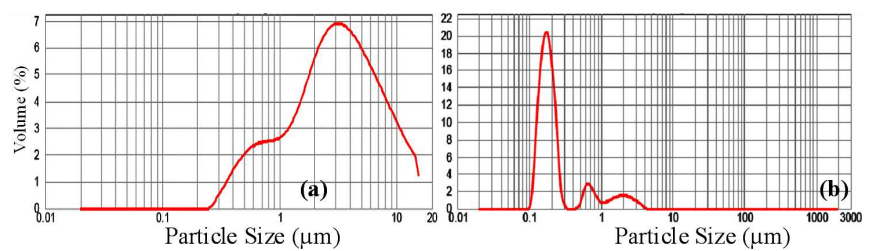

Fig. 2. Particle size distribution of (a) unmilled and (b) 30 min milled boron carbide.

\section{Results and discussion}

Experimental results for $8515,8515 \_1 / 2$ and $8515 \_\mathrm{M}$ boron carbide-titanium diboride composites at different thicknesses with Cs-137 gamma source are given in Table II.

Using the values in the tables, relative intensitymaterial thickness graphs were drawn for all boron carbide-titanium diboride composites. Exponentially fitted equations were calculated. Figure 3 shows relative intensity-material thickness graphs of all boron carbidetitanium diboride composites.

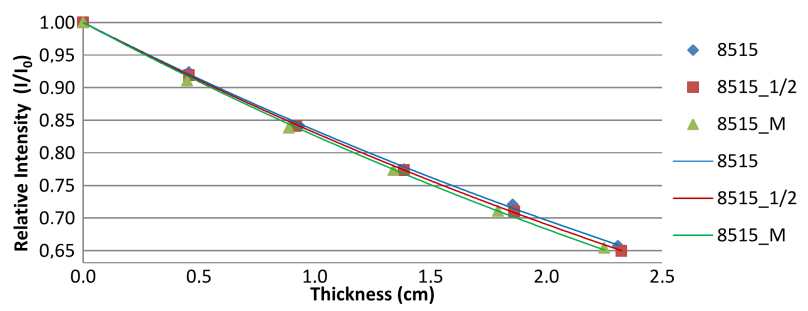

Fig. 3. Relative intensity for titanium diboride reinforced boron carbide-silicon carbide composites.

TABLE III

The linear and mass attenuation coefficients of 8515 , 8515-1/2 and 8515-M composite materials.

\begin{tabular}{c|c|c|c|c}
\hline \hline \multirow{2}{*}{$\begin{array}{c}\text { Material } \\
\text { (code) }\end{array}$} & $\begin{array}{c}\text { Linear } \\
\text { attenuation } \\
\text { coefficient } \\
{\left[\mathrm{cm}^{-1}\right]}\end{array}$ & \multicolumn{2}{|c}{$\begin{array}{c}\text { Mass attenuation coefficient } \\
{\left[10^{-2} \mathrm{~cm}^{2} / \mathrm{g}\right]}\end{array}$} \\
\cline { 3 - 5 } & $\begin{array}{c}\text { Experi- } \\
\text { mentally }\end{array}$ & XCOM & $\%$ diff. \\
\hline 8515 & 0.181 & 6.741 & 7.254 & 7.07 \\
$8515-1 / 2$ & 0.185 & 6.817 & 7.254 & 6.02 \\
$8515-\mathrm{M}$ & 0.191 & 6.943 & 7.254 & 4.29
\end{tabular}

Using the graphs in Fig. 3 the linear attenuations of the composite materials and correlation coefficients were calculated. The mass attenuation coefficients $(\mu / \rho)$ of the composite materials were calculated. Theoretical mass attenuation coefficient value for $85 \%$ boron carbide- $15 \%$ titanium diboride composite was calculated from XCOM computer code [9]. The values compared with each other for all materials and the difference percentages were calculated. The linear and attenuation coefficient values of the composites and difference percentages are given in Table III.

It could be seen in Table III that the decrease of boron carbide particle size in boron carbide-titanium diboride composite materials causes higher linear attenuation values. In addition from Table III it can be stated that the decrease of the particle size of boron carbide in boron carbide-titanium diboride composites causes higher mass attenuation coefficient values and closing the theoretical values. Also the difference percentage decreases with small boron carbide particle size.

\section{Acknowledgments}

The authors wish to thank BMBT Co. for their support about production of materials.

\section{References}

[1] A.C. Akarsu, M.Sc. Thesis, ITU Institute of Science and Technology, Istanbul 2009.

[2] F. Thevenot, J. Europ. Ceram. Soc. 6, 205 (1990)

[3] N. Cho, Ph.D. Thesis, Georgia Institute of Technology, 2006.

[4] E. Turan, M.Sc. Thesis, ITU Institute of Science and Technology, Istanbul 2004.

[5] S. Aktop, M.Sc. Thesis, ITU Institute of Science and Technology, Istanbul 2010.

[6] R. Halmshaw, Non-Destructive Testing, E. Arnold, London 1991.

[7] B. Büyük, A.B. Tuğrul, in: X. Nat. Nuclear Science and Technologies Congress, Mugla, Full Text Books, Vol.1, Mugla 2009, p. 49.

[8] G. Földiak, Industrial Application of Radioisotopes, Elsevier, Amsterdam 1986.

[9] M.J. Berger, J.H. Hubbell, S.M. Seltzer, J. Chang, J.S. Coursey, R. Sukumar, D.S. Zucker, K. Olsen, XCOM: photon crossection database, http://www . nist.gov/pml/data/xcom/index.cfm U.S. 